\title{
PENERAPAN METODE GENERALIZED STRUCTURED COMPONENT ANALYSIS PADA KEPUASAN KONSUMEN (Studi Kasus: Pasien Klinik Q)
}

\author{
Farisiyah Fitriani $^{1}$, Agus Rusgiyono ${ }^{2}$, Tatik Widiharih ${ }^{3}$ \\ 1,2,3 Departemen Statistika, Fakultas Sains dan Matematika, Universitas Diponegoro \\ Email: farisiyah.fitriani02@gmail.com
}

\begin{abstract}
Customer satisfaction is used by a company to evaluate products or services whether it is sufficient with customer's expectations. Satisfaction is influenced by factors that cannot be measured directly are called latent variables and can be measured through indicators used to measure satisfaction with Structural Equation Modeling (SEM). Generalized Structured Component Analysis (GSCA) method is part of a SEM based on a variant that does not require the assumption of a multivariate normal distribution and has a measure overall goodness of fit. The parameters used are factor loading, coefficients parameter, and weight of indicators and estimated with alternating least square. The type of data used primary data from the results of the questionnaire with stratified proportional random sampling and number of samples 286. This research using indicators as measurable variables as many 32 indicators and 8 latent variable. Considering to the evaluation of the structural model, it is found there are 5 variables that influence satisfaction, they are prices, quality yield, cleanliness, doctor's services, and employee services with a large influence of $77.18 \%$ and the impact of satisfaction on loyalty is $48.63 \%$. For the overall goodness of fit measure, it is known that the FIT value is $63.75 \%$ and the adjusted FIT (AFIT) value is $63.47 \%$. The goodness offit (GFI) produced the value in the amount of $96.43 \%$, indicating that the general model has the good level of compatibility.
\end{abstract}

Keywords: Generalized Structured Component Analysis, Structural Equation Modeling, Overall goodness of fit, Alternating Least Square, Stratified Proportional Random Sampling

\section{PENDAHULUAN}

Kepuasan konsumen adalah penilaian seseorang terhadap produk atau jasa dalam menilai apakah produk atau jasa tersebut telah sesuai dengan kebutuhan dan keinginan konsumen (Kotler dalam (Almsalam, 2014)). Kepuasan terkdang dipengaruhi oleh faktor-faktor yang tidak dapat diukur secara langsung sehingga diperlukan indikator atau variabel terukur yang digunakan untuk mengukur kepuasan tersebut. Klinik sebagai fasilitas pelayanan kesehatan menyelenggarakan pelayanan kesehatan perorangan yang menyediakan pelayanan medis dasar dan/atau spesialistik memberikan peranan penting untuk mewujudkan tingkat kesehatan masyarakat yang baik. Statistika memberikan peranan penting dalam dunia pendidikan atau riset untuk menganalisis suatu kasus atau permasalahan. Structural Equation Modeling (SEM) merupakan salah satu metode statistika analisis multivariat generasi kedua setelah analisis regresi, analisis diskriminan, analisis faktor atau analisis komponen utama. Metode ini digunakan untuk mengukur spesifikasi dan analisis saling ketergantungan/hubungan antara variabel. SEM telah menjadi alat yang popular karena sifat fleksibel dan generalisasi dalam analisisnya. SEM dapat digunakan untuk variabel berbentuk laten atau variabel tidak terukur secara langsung

SEM berbasis varian terdiri dari 2 jenis metode yaitu Partial Least Square (PLS) dan Generalized Structured Component Analysis (GSCA). Pada PLS memiliki kelemahan yaitu tidak memiliki ukuran goodness-fit model sehingga sulit untuk mengetahui seberapa baik model cocok dengan data yang ada. Metode Generalized Structured Component Analysis 
diusulkan untuk melengkapi kekurangan pada Partial Least Square di mana tetap mempertahankan kelebihan dari PLS yaitu tidak tergantung pada asumsi normalitas dan dilengkapi dengan ukuran overall goodness-fit model. Pada penelitian ini digunakan pemprograman $\mathrm{R}$ sebagai software pengolahan data dengan tujuan untuk membentuk model dan mengetahui faktor-faktor yang memengaruhi kepuasan dan loyalitas dengan metode Generalized Structured Component Analysis.

\section{TINJAUAN PUSTAKA}

Generalized Structured Component Analysis (GSCA) merupakan metode Structural Equation Modeling berbasis varian dimana tidak terpaut dengan asumsi distribusi normalitas multivariate. Metode ini diusulkan oleh Hwang dan Takane (2004) sebagai solusi untuk mengatasi kelemahan dari metode PLS dimana pada metode PLS tidak ada pengujian tidak dapat menyelesaikan masalah optimasi global untuk parameter estimasinya sehingga sulit untuk mengevaluasi model secara keseluruhan atau memeriksa seberapa baik model cocok. Menurut Hwang (2010), GSCA dipandang sebagai SEM berbasis komponen di mana variabel laten didefinisikan sebagai komponen dari variabel teramati dengan persamaan sebagai berikut:

$$
\gamma_{i}=W z_{i}
$$

dimana, $\boldsymbol{\gamma}_{\boldsymbol{i}}$ adalah vektor berukuran $d x \boldsymbol{l}$ dari variabel laten atau komponen ke-i, $\boldsymbol{z}_{\boldsymbol{i}}$ adalah vektor berukuran $j \times l$ dari variabel terukur atau indikator ke-i, dan $\boldsymbol{W}$ adalah matrik berukuran $d x j$ yang terdiri dari bobot indikator dari variabel terukur.

GSCA juga meliputi dua persamaan untuk spesifikasi model yaitu model pengukuran atau outer model yang menggambarkan hubungan antara indikator dan variabel laten dan model struktural atau inner model yang digunakan untuk menentukan hubungan antara variabel laten. Secara matematis model pengukuran dituliskan sebagai berikut:

$$
\boldsymbol{z}_{\boldsymbol{i}}=\boldsymbol{C} \boldsymbol{\gamma}_{\boldsymbol{i}}+\boldsymbol{\varepsilon}_{\boldsymbol{i}}
$$

dimana, $\mathbf{C}$ adalah matrik loading berukuran $j x d$ antara variabel laten dan indikator, dan $\boldsymbol{\varepsilon}_{\boldsymbol{i}}$ adalah vektor berukuran $j \times 1$ dari residual untuk $\boldsymbol{z}_{\boldsymbol{i}}$

Sedangkan model struktural dinyatakan seperti di bawah ini:

$$
\gamma_{i}=B \gamma_{i}+\xi_{i}
$$

dimana, $\mathbf{B}$ adalah matrik berukuran $\mathrm{d} \mathrm{x}$ d dari koefisien jalur dari variabel laten, dan $\xi_{i}$ adalah vektor berukuran $\mathrm{d} \times 1$ dari residual untuk $\boldsymbol{\gamma}_{\boldsymbol{i}}$

Berdasarkan ketiga persamaan diatas dapat diintegrasikan menjadi satu persamaan sebagai berikut:

di mana, $\mathrm{V}=\left[\begin{array}{c}\boldsymbol{I} \\ \boldsymbol{W}\end{array}\right], \mathrm{A}=\left[\begin{array}{l}\boldsymbol{C} \\ \boldsymbol{B}\end{array}\right]$, dan $\mathrm{e}_{\mathrm{i}}=\left[\begin{array}{l}\boldsymbol{\varepsilon}_{\boldsymbol{i}} \\ \boldsymbol{\xi}_{\boldsymbol{i}}\end{array}\right]$

$$
\begin{aligned}
{\left[\begin{array}{l}
Z_{i} \\
\gamma_{i}
\end{array}\right] } & =\left[\begin{array}{l}
C \\
B
\end{array}\right] \gamma_{i}+\left[\begin{array}{l}
\varepsilon_{i} \\
\xi_{i}
\end{array}\right] \\
{\left[\begin{array}{c}
I \\
W
\end{array}\right] z_{i} } & =\left[\begin{array}{l}
C \\
B
\end{array}\right] W z_{i}+\left[\begin{array}{c}
\varepsilon_{i} \\
\xi_{i}
\end{array}\right]
\end{aligned}
$$

Parameter yang tidak diketahui dari Generalized Structured Component Analysis yaitu ( $\mathbf{V}, \mathbf{W}$, dan $\mathbf{A})$ sehingga diperkirakan sedemikian rupa agar jumlah kuadrat dari semua resid $\left(\mathbf{e}_{\mathbf{i}}\right)$ sekecil mungkin. Hal ini sama dengan meminimumkan kriteria least square berikut ini:

$$
\phi=\sum_{i=1}^{n}\left(\mathbf{V z} z_{i}-\mathrm{AWz}_{i}\right)^{t}\left(\mathrm{Vz}_{i}-\mathbf{A W} z_{i}\right)
$$

Evaluasi model GSCA dilakukan melalui tiga tahap, antara lain: 


\section{Kecocokan model pengukuran (outer model)}

Convergent validity dinilai berdasarkan nilai loading factor masing-masing indikator pembentuk konstruk laten. Suatu konstruk laten nilai valid atau baik jika nilai estimasi loading factor lebih dari 0,5 (Ghozali, 2013). Discriminant validity dinilai dengan membandingkan nilai $\sqrt{A V E}$ setiap konstruk laten dengan korelasi antara variabel bersangkutan dengan variabel lainnya dalam model. Apabila nilai akar kuadrat AVE setiap variabel lebih besar daripada nilai korelasi antara variabel dengan variabel lainnya dalam model maka dapat dikatakan memiliki nilai discriminant validity yang baik (Ghozali,2013). Berikut rumus menghitung AVE:

$$
\mathrm{AVE}=\frac{\sum_{j=1}^{h} c_{i j}^{2}}{\sum_{j=1}^{h} c_{i j}^{2}+\sum_{j=1}^{h}\left(1-c_{i j}^{2}\right)}
$$

Composite reliability mengukur suatu konstruk laten dapat dievaluasi dengan dua macam ukuran yaitu internal consistency dan cronbach alpha. Nilai composite reliability yang direkomendasikan lebih besar atau sama dengan 0,7. Composite reliability dapat dihitung dengan rumus

$$
p c=\frac{\left(\sum_{j=1}^{h} c_{i j}\right)^{2}}{\left(\sum_{j=1}^{h} c_{i j}\right)^{2}+\sum_{j=1}^{h}\left(1-c_{i j}^{2}\right)}
$$

Selain melihat dari nilai $p c$, composite reliability dapat dilakukan melalui uji hipotesis. Indikator dinyatakan valid apabila nilai loadingnya memiliki nilai CR yang signifikan. Pengujian dilakukan sebagai berikut:

Hipotesis:

$\mathrm{H}_{0}: \mathrm{c}_{\mathrm{ij}}=0$, yaitu loading indikator tidak reliabel

$\mathrm{H}_{1}: \mathrm{c}_{\mathrm{ij}} \neq 0$, yaitu loading indikator reliabel

Statistik uji:

$$
C R l=\frac{c_{i j}}{S E\left(c_{i j}\right)}
$$

$\mathrm{H}_{0}$ ditolak apabila nilai $|\mathrm{CR} 1| \geq 2,0$ dengan tingkat kesalahan $\alpha$ berarati nilai estimasi loading setiap indikator reliabel.

\section{Kecocokan model struktural (inner model)}

Model struktural dievaluasi dengan uji signifikansi parameter dan nilai R-square. Uji signifikansi parameter digunakan untuk mengetahui apakah koefisien dari masing-masing variabel eksogen signifikan memengaruhi atau tidak. Pengujian signifikansi parameter sebagai berikut:

Hipotesis:

$\mathrm{H}_{0}: b_{i}=0$, yaitu koefisien parameter $\gamma_{i}$ tidak signifikan

$\mathrm{H}_{1}: b_{i} \neq 0$, yaitu koefisien parameter $\gamma_{i}$ signifikan

Statistik uji:

$$
C R b=\frac{b_{i}}{S E\left(b_{i}\right)}
$$

Kriteria uji:

$\mathrm{H}_{0}$ ditolak apabila nilai $|\mathrm{CRb}| \geq 2,0$ dengan tingkat kesalahan $\alpha$ berarati koefisien parameter signifikan.

Nilai $R$-square adalah kuadrat dari korelasi yang menjelaskan proporsi varian variabel endogen yang dijelaskan oleh model (Hwang et al, 2015). Rumus $R$-square sebagai berikut:

$$
R^{2}=1-\frac{\sum_{i=1}^{n} e_{i}{ }^{2}}{n}
$$


dengan, $\mathrm{R}^{2}$ adalah nilai $R$-square, $\mathrm{e}_{\mathrm{i}}$ adalah nilai residual responden ke-i dan $\mathrm{n}$ adalah banyaknya data.

\section{Kecocokan model keseluruhan (overall goodness of fit)}

FIT merupakan proporsi dari total varian semua variabel endogen yang dijelaskan oleh suatu model tertentu (Hwang, 2010). FIT digunakan untuk menjelaskan ketidakcocokan antara model dan data. Nilainya berkisar 0 sampai 1 di mana semakin besar nilai FIT, semakin baik model yang dihasilkan. Pengukuran FIT merupakan fungsi dari jumlah residu kuadrat antara model dan data. Nilai FIT dipengaruhi oleh kompleksitas model yaitu semakin banyak parameter semakin besar nilai FIT. Nilai FIT sangat sensitif terhadap kompleksitas model sehingga perlu dilihat juga nilai adjusted FIT (AFIT). AFIT digunakan untuk membandingkan model. Menurut Hwang (2010), model yang memaksimalkan AFIT dapat dianggap sebagai model terbaik. Nilai GFI menunjukkan tingkat kecocokan estimasi model. Menurut Ghozali (2013), nilai GFI yang baik adalah lebih dari 90\%.

\section{METODE PENELITIAN}

\subsection{Jenis dan Sumber Data}

Data yang digunakan dalam penelitian ini adalah data sekunder dan data primer. Data sekunder dalam hal ini yaitu database pasien Klinik Q. Data primer yang digunakan berupa kuesioner offline dan online (googleform) kepada pasien Klinik Q yang terpilih secara acak. Klinik Q dalam hal ini adalah nama samaran dari sebuah klinik di suatu kota.

\subsection{Populasi dan Sampel}

Penelitian ini mengambil sampel sebanyak 286 pasien yang terdiri dari 108 pasien pengguna BPJS dan 178 pasien non BPJS/mandiri. Ukuran tersebut ditentukan dengan menggunakan rumus slovin. Pengambilan data dilaksanakan dari bulan Januari-Februari 2020 .

\subsection{Metode Pengambilan Sampel}

Metode pengambilan sampel dalam penelitian ini menggunakan metode sampel acak stratifikasi (Stratified random sampling) dengan alokasi proporsional, di mana peneliti membagi data menjadi 2 kelompok yaitu kelompok BPJS dan kelompok non BPJS/mandiri. Lalu dari masing-masing kelompok diambil sejumlah sampel untuk diacak dan dipilih menjadi responden.

\subsection{Variabel Penelitian}

Variabel yang digunakan dalam penelitian ini terdiri dari 8 variabel laten dan di dalam setiap variabel laten terdapat beberapa indikator diantaranya 2 indikator untuk menjelaskan variabel laten kualitas hasil $\left(\gamma_{2}\right), 4$ indikator untuk menjelaskan variabel laten harga $\left(\gamma_{1}\right)$, fasilitas klinik $\left(\gamma_{3}\right)$, kebersihan $\left(\gamma_{4}\right)$, pelayanan dokter $\left(\gamma_{5}\right)$, pelayanan pegawai $\left(\gamma_{6}\right)$, dan loyalitas $\left(\gamma_{8}\right), 6$ indikator untuk menjelaskan variabel laten kepuasan $\left(\gamma_{7}\right)$.

\subsection{Model Penelitian}

Model penelitian dengan indikator-indikator penyusun variabel laten secara keseluruhan dapat dilihat sebagai berikut:

Model pengukuran yang terbentuk yaitu:

$\mathrm{z}_{1}=\mathrm{c}_{1} \gamma_{1}+\varepsilon_{1}$

$\mathrm{z}_{32}=\mathrm{c}_{32} \gamma_{8}+\varepsilon_{32}$

Pada penelitian ini terdapat dua persamaan model struktural dengan variabel endogen

kepuasan $\left(\gamma_{7}\right)$ dan loyalitas $\left(\gamma_{8}\right)$ yang terbentuk sebagai berikut:

$\gamma_{7}=b_{1} \gamma_{1}+b_{2} \gamma_{2}+b_{3} \gamma_{3}+b_{4} \gamma_{4}+b_{5} \gamma_{5}+b_{6} \gamma_{6}+\xi_{1}$

$\gamma_{8}=b_{7} \gamma_{7}+\xi_{2}$

\subsection{Tahapan Analisis Data}


1. Menentukan latar belakang dari permasalahan yang akan diambil dari penelitian.

2. Merumuskan permasalahan apa saja yang akan dilakukan dalam penelitian.

3. Menentukan tujuan dilakukan penelitian.

4. Melakukan studi observasi dan literatur.

5. Mengumpulkan informasi-informasi yang berkaitan dengan penelitian dan variabel yang akan digunakan.

6. Mendesain teknik sampling dan kuesioner yang akan digunakan.

7. Melakukan survei pendahuluan.

8. Uji validitas dan reliabilitas terhadap hasil survei pendahuluan. Apabila hasilnya valid dan reliabel maka dapat dilanjutkan dengan survei untuk semua sampel yang terpilih. Namun, apabila hasilnya tidak valid dan reliabel maka perlu dilakukan kaji ulang terhadap desain kuesioner.

9. Identifikasi model yang digunakan dalam penelitian.

10. Mengestimasi parameter yang digunakan.

11. Evaluasi model pengukuran.

12. Evaluasi model struktural.

13. Menghitung overall model fit.

14. Interpretasi model.

\section{HASIL DAN PEMBAHASAN}

Pada penelitian ini digunakan 6 variabel laten eksogen dan 2 variabel laten endogen. Pada pengolahan data awal diketahui bahwa ada 1 variabel laten eksogen yaitu variabel kualitas hasil secara signifikan tidak memengaruhi variabel kepuasan sehingga dilakukan penghapusan jalur atau penghapusan variabel terdapat variabel kualitas hasil $\left(\gamma_{3}\right)$. Setelah dilakukan pengolahan data kembali di dapatkan hasil sebagai berikut:

\subsection{Evaluasi model pengukuran}

\section{Convergent validity}

Pengujian convergent validity dilakukan dengan melihat nilai estimasi loading, convergent validity terpenuhi apabila nilai estimasi loadingnya lebih besardari 0,5 (Ghozali, 2013). Berdasarkan perhitungan diperoleh bahwa nilai estimasi loading masing-masing indikator pada tabel 1 . lebih dari 0,5 sehingga convergent validity terpenuhi.

Tabel 1. Nilai Estimasi Loadings Model Pengukuran

\begin{tabular}{lllll}
\hline & Estimate & Std.Error & 95\%CI_LB & 95\%CI_UB \\
\hline $\mathrm{Z}_{11}$ & 0.8015 & 0.0274 & 0.7422 & 0.8557 \\
$\mathrm{Z}_{12}$ & 0.8787 & 0.0169 & 0.8446 & 0.9098 \\
$\mathrm{Z}_{13}$ & 0.8721 & 0.0215 & 0.825 & 0.9078 \\
$\mathrm{Z}_{14}$ & 0.8778 & 0.0165 & 0.8402 & 0.9088 \\
$\mathrm{Z}_{21}$ & 0.9366 & 0.0102 & 0.9137 & 0.9551 \\
$\mathrm{Z}_{22}$ & 0.937 & 0.0096 & 0.9162 & 0.9548 \\
$\mathrm{Z}_{41}$ & 0.9062 & 0.0198 & 0.8572 & 0.9373 \\
$\mathrm{Z}_{42}$ & 0.923 & 0.0136 & 0.8925 & 0.9466 \\
$\mathrm{Z}_{43}$ & 0.9049 & 0.0166 & 0.8691 & 0.9325 \\
$\mathrm{Z}_{44}$ & 0.8113 & 0.0239 & 0.7579 & 0.856 \\
$\mathrm{Z}_{51}$ & 0.8481 & 0.0272 & 0.7892 & 0.8935 \\
$\mathrm{Z}_{52}$ & 0.9115 & 0.0137 & 0.8801 & 0.9328 \\
$\mathrm{Z}_{53}$ & 0.897 & 0.0174 & 0.858 & 0.9242 \\
$\mathrm{Z}_{54}$ & 0.8577 & 0.0225 & 0.8032 & 0.8945 \\
$\mathrm{Z}_{61}$ & 0.9022 & 0.0138 & 0.8735 & 0.9263 \\
$\mathrm{Z}_{62}$ & 0.8963 & 0.0139 & 0.8658 & 0.9211 \\
$\mathrm{Z}_{63}$ & 0.9017 & 0.0133 & 0.8712 & 0.9255 \\
\hline
\end{tabular}




\begin{tabular}{lllll}
\hline $\mathrm{Z}_{64}$ & 0.8367 & 0.0224 & 0.7899 & 0.876 \\
$\mathrm{Z}_{71}$ & 0.7683 & 0.0271 & 0.7037 & 0.8137 \\
$\mathrm{Z}_{72}$ & 0.8631 & 0.0171 & 0.8299 & 0.8953 \\
$\mathrm{Z}_{73}$ & 0.8405 & 0.0204 & 0.7972 & 0.8781 \\
$\mathrm{Z}_{74}$ & 0.8099 & 0.024 & 0.7583 & 0.8535 \\
$\mathrm{Z}_{75}$ & 0.6468 & 0.056 & 0.5294 & 0.734 \\
$\mathrm{Z}_{76}$ & 0.7783 & 0.0303 & 0.7146 & 0.8274 \\
$\mathrm{Z}_{81}$ & 0.9166 & 0.0135 & 0.8888 & 0.9417 \\
$\mathrm{Z}_{82}$ & 0.9202 & 0.0122 & 0.8928 & 0.9419 \\
$\mathrm{Z}_{83}$ & 0.898 & 0.0151 & 0.8686 & 0.9279 \\
$\mathrm{Z}_{84}$ & 0.8768 & 0.0247 & 0.8216 & 0.9169 \\
\hline
\end{tabular}

\section{Discriminant validity}

Nilai $\sqrt{A V E}$ dan nilai korelasi masing-masing variabel laten terhadap variabel laten lainnya digunakan untuk pengujian discriminant validity. Apabila nilai $\sqrt{A V E}$ pada variabel laten lebih besar dibandingkan nilai korelasi dari variabel laten lainnya maka pengujian discriminant validity terpenuhi. Berdasarkan perhitungan diperoleh bahwa nilai $\sqrt{A V E}$ setiap variabel laten pada tabel 2. lebih besar dibandingkan dengan nilai korelasi terhadap variabel laten lainnya sehingga telah memenuhi pengujian discriminant validity. 
Tabel 2. Nilai korelasi dan $\sqrt{A V E}$ Model Pengukuran

\begin{tabular}{|c|c|c|c|c|c|c|c|}
\hline & Harga & $\begin{array}{c}\text { Kualitas } \\
\text { hasil }\end{array}$ & Kebersihan & $\begin{array}{c}\text { Pelayanan } \\
\text { dokter }\end{array}$ & $\begin{array}{c}\text { Pelayanan } \\
\text { Pegawai }\end{array}$ & $\begin{array}{l}\text { Kepu- } \\
\text { as an }\end{array}$ & $\begin{array}{l}\text { Loya- } \\
\text { litas }\end{array}$ \\
\hline Harga & $\mathbf{0 , 8 5 8}$ & & & & & & \\
\hline $\begin{array}{c}\text { Kualitas } \\
\text { hasil }\end{array}$ & 0,3944 & $\mathbf{0 , 9 3 7}$ & & & & & \\
\hline Kebersihan & 0,5065 & 0,3861 & $\mathbf{0 , 8 8 7}$ & & & & \\
\hline $\begin{array}{c}\text { Pelayanan } \\
\text { dokter }\end{array}$ & 0,4241 & 0,5021 & 0,5679 & $\mathbf{0 , 8 7 9}$ & & & \\
\hline $\begin{array}{c}\text { Pelayanan } \\
\text { pegawai }\end{array}$ & 0,5444 & 0,3325 & 0,5257 & 0,3804 & $\mathbf{0 , 8 8 5}$ & & \\
\hline Kepuasan & 0,6811 & 0,5539 & 0,6781 & 0,7183 & 0,6418 & $\mathbf{0 , 7 8 8}$ & \\
\hline Loyalitas & 0,4695 & 0,5245 & 0,5726 & 0,6202 & 0,441 & 0,6974 & $\mathbf{0 , 9 0 3}$ \\
\hline
\end{tabular}

\section{Composite reliability}

Composite reliability digunakan untuk mengukur reliabilitas dari setiap indikator. Nilai composite reliability yang direkomendasikan lebih besar atau sama dengan 0,7

Tabel 3. Nilai Composite Reliability Model Pengukuran

\begin{tabular}{cc}
\hline Variabel & Nilai $\boldsymbol{p c}$ \\
\hline Harga & 0,918 \\
\hline Kualitas hasil & 0,935 \\
\hline Kebersihan & 0,937 \\
\hline Pelayanan dokter & 0,931 \\
\hline Pelayanan pegawai & 0,935 \\
\hline Kepuasan & 0,907 \\
\hline Loyalitas & 0,946
\end{tabular}

Berdasarkan perhitungan diperoleh bahwa nilai composite reliability setiap variabel laten pada tabel 3. memiliki nilai lebih besar atau sama dengan dari 0,7 sehingga pengujian composite reliability terpenuhi. Selain itu, pengujian composite reliability dapat dilakukan dengan uji hipotesis nilai loading masing-masing indikator sebagai berikut:

Hipotesis:

$\mathrm{H}_{0}: \mathrm{c}_{\mathrm{ij}}=0$, yaitu loading indikator tidak signifikan/tidak reliabel

$\mathrm{H}_{1}: \mathrm{c}_{\mathrm{ij}} \neq 0$, yaitu loading indikator signifikan dan reliabel

Statistik uji:

Kriteria uji:

$$
C R l=\frac{c_{i j}}{S E\left(c_{i j}\right)}
$$

$\mathrm{H}_{0}$ ditolak apabila nilai $|\mathrm{CR}| \geq 2,0$ (Hwang, 2010) dengan tingkat kesalahan 5\% berarati nilai estimasi loading setiap indikator reliabel dan signifikan.

Analisis:

Berdasarkan perhitungan rumus $\mathrm{CR}_{1}$ diperoleh nilai $\mathrm{CR}_{1}$ masing-masing indikator pada tabel 4. lebih besar dari 2 sehingga nilai loading setiap indikator reliabel. 
Tabel 4. Nilai Estimasi Loading Model Pengukuran

\begin{tabular}{|c|c|c|c|}
\hline Indikator & Estimate & Std. Error & CRl \\
\hline $\mathrm{Z}_{11}$ & 0,8015 & 0,0274 & 29,252 \\
\hline $\mathrm{Z}_{12}$ & 0,8787 & 0,0169 & 51,994 \\
\hline $\mathrm{Z}_{13}$ & 0,8721 & 0,0215 & 40,563 \\
\hline $\mathrm{Z}_{14}$ & 0,8778 & 0,0165 & 53,200 \\
\hline $\mathrm{Z}_{21}$ & 0,9366 & 0,0102 & 91,824 \\
\hline $\mathrm{Z}_{22}$ & 0,937 & 0,0096 & 97,604 \\
\hline $\mathrm{Z}_{41}$ & 0,9062 & 0,0198 & 45,768 \\
\hline $\mathrm{Z}_{42}$ & 0,923 & 0,0136 & 67,868 \\
\hline $\mathrm{Z}_{43}$ & 0,9049 & 0,0166 & 54,512 \\
\hline $\mathrm{Z}_{44}$ & 0,8113 & 0,0239 & 33,946 \\
\hline $\mathrm{Z}_{51}$ & 0,8481 & 0,0272 & 31,180 \\
\hline $\mathrm{Z}_{52}$ & 0,9115 & 0,0137 & 66,533 \\
\hline $\mathrm{Z}_{53}$ & 0,897 & 0,0174 & 51,552 \\
\hline $\mathrm{Z}_{54}$ & 0,8577 & 0,0225 & 38,120 \\
\hline $\mathrm{Z}_{61}$ & 0,9022 & 0,0138 & 65,377 \\
\hline$Z_{62}$ & 0,8963 & 0,0139 & 64,482 \\
\hline $\mathrm{Z}_{63}$ & 0,9017 & 0,0133 & 67,797 \\
\hline $\mathrm{Z}_{64}$ & 0,8367 & 0,0224 & 37,353 \\
\hline$Z_{71}$ & 0,7683 & 0,0271 & 28,351 \\
\hline $\mathrm{Z}_{72}$ & 0,8631 & 0,0171 & 50,474 \\
\hline $\mathrm{Z}_{73}$ & 0,8405 & 0,0204 & 41,201 \\
\hline$Z_{74}$ & 0,8099 & 0,024 & 33,746 \\
\hline $\mathrm{Z}_{75}$ & 0,6468 & 0,056 & 11,550 \\
\hline $\mathrm{Z}_{76}$ & 0,7783 & 0,0303 & 25,686 \\
\hline $\mathrm{Z}_{81}$ & 0,9166 & 0,0135 & 67,896 \\
\hline $\mathrm{Z}_{82}$ & 0,9202 & 0,0122 & 75,426 \\
\hline $\mathrm{Z}_{83}$ & 0,898 & 0,0151 & 59,470 \\
\hline $\mathrm{Z}_{84}$ & 0,8768 & 0,0247 & 35,498 \\
\hline
\end{tabular}

Berdasarkan evaluasi kecocokan model di atas diketahui bahwa setiap indikator penjelas variabel laten telah valid dan reliabel sehingga indikator dapat dipercaya dan benar mengukur masing-masing variabel latennya.

\subsection{Evaluasi Kecocokan Model Struktural}

\section{Uji signifikansi parameter}

Hipotesis:

$\mathrm{H}_{0}: b_{i}=0$, yaitu koefisien parameter $\gamma_{i}$ tidak signifikan

$\mathrm{H}_{1}: b_{i} \neq 0$, yaitu koefisien parameter $\gamma_{i}$ signifikan

Statistik uji:

$C R b=\frac{b_{i}}{S E\left(b_{i}\right)}$

Kriteria uji:

$\mathrm{H}_{0}$ ditolak apabila nilai $|\mathrm{CRb}| \geq 2,0$ (Hwang, 2010) dengan tingkat kesalahan $5 \%$ berarati koefisien parameter signifikan. 
Berdasarkan perhitungan rumus $\mathrm{CRb}$ diperoleh nilai $\mathrm{CRb}$ pada tabel 5. untuk variabel laten harga, kualitas hasil, pelayanan dokter, kebersihan dan pelayanan pegawai terhadap kepuasan dan nilai $\mathrm{CRb}$ variabel laten kepuasan terhadap loyalitas memiliki nilai lebih besar dari 2 sehingga koefisien parameter signifikan, sedangkan untuk variabel fasilitas klinik memiliki nilai CRb kurang dari 2 sehingga koefisien parameter tidak signifikan.

Tabel 5. Nilai Koefisien Parameter Model Struktural

\begin{tabular}{cccc}
\hline & $\begin{array}{c}\text { Koefisien } \\
\text { parameter }\end{array}$ & Standar eror & CRb \\
\hline Harga terhadap kepuasan & 0,2696 & 0,0512 & 5,26563 \\
\hline Kualitas hasil terhadap kepuas an & 0,1268 & 0,0362 & 3,50276 \\
\hline Kebersihan terhadap kepuasan & 0,1701 & 0,0466 & 3,65021 \\
\hline Pelayanan dokter terhadap kepuasan & 0,3568 & 0,0606 & 5,88779 \\
\hline Pelayanan pegawai terhadap kepuasan & 0,228 & 0,0487 & 4,68172 \\
\hline Kepuasan terhadap loyalitas & 0,6973 & 0,0382 & 18,25393 \\
\hline
\end{tabular}

Sehingga persamaan model yang terbentuk sebagai berikut:

$\gamma_{7}=b_{1} \gamma_{1}+b_{2} \gamma_{2}+b_{4} \gamma_{4}+b_{5} \gamma_{5}+b_{6} \gamma_{6}+\xi_{1}$

$\gamma_{7}=0,2696 \gamma_{1}+0,1268 \gamma_{2}+0,1701 \gamma_{4}+0,3568 \gamma_{5}+0,228 \gamma_{6}+\xi_{1}$

$\gamma_{8}=\mathrm{b}_{7} \gamma_{7}+\xi_{2}$

$\gamma_{8}=0,6973 \gamma_{7}+\xi_{2}$

\section{Nilai R-square}

Pada penelitian ini diperoleh nilai $\mathrm{R}$-square sebesar 0,7718 yang artinya variabel kepuasan dapat dijelaskan oleh variabel laten harga, kualitas hasil, kebersihan, pelayanan dokter, pelayanan pegawai sebesar $77,18 \%$ dan $22,82 \%$ dipengaruhi oleh variabel lain. Besar nilai R-square untuk variabel loyalitas sebesar 0,4863 yang artinya variabel loyalitas dapat dijelaskan oleh variabel kepuasan sebesar $48,63 \%$ dan $51,37 \%$ dipengaruhi oleh variabel lain.

\subsection{Evaluasi Overall Goodness of Fit}

Pada penelitian in diperoleh bahwa nilai FIT sebesar 0,6375 yang artinya model secara keseluruhan mampu menjelaskan variasi dari data sebesar 63,75\% dan nilai Adjusted FIT (AFIT) sebesar 63,47\% dipengaruhi oleh kompleksitas model. Nilai Goodness of Fit (GFI) yang dihasilkan sebesar 0,9626 atau 96,26\% menunjukkan model secara keseluruhan memiliki tingkat kecocokan yang baik.

\section{KESIMPULAN}

Berdasarkan hasil analisis dan pembahasan diperoleh kesimpulan yaitu pada pengolahan data model awal terdapat satu variabel tidak signifikan memengaruhi kepuasan sehingga variabel tersebut dihilangkan dari model sehingga persamaan model yang terbentuk untuk variabel endogen kepuasan $\gamma_{7}=0,2696 \gamma_{1}+0,1268 \gamma_{2}+0,1701 \gamma_{4}+0,3568$ $\gamma_{5}+0,228 \gamma_{6}+\xi_{1}$ dan persamaan model yang terbentuk untuk variabel endogen loyalitas $\gamma_{8}=0,6973 \gamma_{7}+\xi_{2}$. Variabel kepuasan dapat dipengaruhi secara signifikan oleh variabel harga, kualitas hasil, kebersihan, pelayanan dokter, dan pelayanan pegawai dengan besar variasi dijelaskan sebesar $77,18 \%$ dan $22,82 \%$ dijelaskan oleh variabel lain dan variabel loyalitas dipengaruhi secara signifikan oleh variabel kepuasan dengan besar variasi dijelaskan sebesar $48,63 \%$. 


\section{DAFTAR PUSTAKA}

Aiken, L. R. 1985. Three Coefficients for Analyzing the Reliability and Validity of ratings. Journal Educational and Psychological Measurement. 45: 131-142.

Almsalam, S. 2014. The Effects of Customer Expectation and Perceived Service Quality on Customer Satisfaction. International Journal of Business and Management Invention. 3 (8): 79-84.

Favero, L. P. dan Belfiore, P. 2019. Sampling. Data Science for Business and Decision Making. Academic Press.

Ghozali, I. 2013 Generalized Structured Component Analysis. Semarang: Badan Penerbit Universitas Diponegoro.

Hwang, H., Malhotra, N.K., Kim, Y., Tomiuk, M. A., and Hong, S. 2010. A Comparative Study on Parameter Recovery of Three Approaches to Structural Equation Modeling. Journal of Marketing Research. 47: 699-712.

Hwang, H. and Takane, Y. 2004. Generalized Structured Component Analysis. Psychometrika. 69 (1): 81-99.

Hwang, H., Ho, M. R., and Lee, J. 2010. Generalized Structured Component Analysis with Latent Interactions. The Psychometrika. 75 (2): 228-242.

Henseler, J. 2012. Why Generalized Structured Component Analysis is not Universally Preferable to Structural Equation Modeling. Journal of the Academy Marketing Science. 40: 402-413.

Karras, D. J. 1997. Statistical Methodology: II. Reliability and Validity Assessment in Study Design, Part A. Academic Emergency Medicine. 4 (1):64-71.

Kim, S., Cardwell, R, and Hwang, H.,. 2017. Using R Package gesca for Generalized Structured Component Analysis. Behaviormetrika. 44:3-23

Kuncoro, M. 2003. Metode Riset untuk Bisnis \& Ekonomi. Jakarta: Penerbit Erlangga.

Ramsey, Philip. 1989. Critical Values for Spearman's Rank Order Correlation. Journal of Educational Statistics. 14 (3): 245-253.

Sekaran, U. and Bougie, R. 2016. Research Methods For Business: A SkillBuilding Approach. John Wiley \&Son. 